\title{
Cam Elyaf Dokuma İle Güçlendirilmiş Tabakalı Kaplama Kerestenin Bazı Teknolojik Özellikleri
}

\author{
Bekir Cihad BAL ${ }^{1 *}$, Hamit ÖZYURT ${ }^{2}$ \\ ${ }^{1}$ Kahramanmaraş Sütçü İmam Üniversitesi, Orman Endüstri Mühendisliği, Kahramanmaraş, Türkiye \\ ${ }^{2}$ Kahramanmaraş Sütçü İmam Üniversitesi, Fen Bilimleri Enstitüsü, Kahramanmaraş, Türkiye
}

\begin{abstract}
ÖZET: Cam elyaf malzeme, güçlendirme amacıyla birçok alanda kullanılmaktadır. Bazı araştırmacılar tarafından, ahşap malzemenin cam elyaf kullanılarak güçlendirilmesi hakkında önemli çalışmalar yapılmıştır. Ancak bu çalışmalarda genel olarak, cam elyaf desteği yük taşıyan elemanların çekme bölgesine uygulanarak, mekanik performansın artırılması amaçlanmıştır. Bu çalışmada, cam elyaf dokuma ve kavak kaplama kullanılarak tabakalı kaplama kereste üretilmiştir. Bir kontrol grubu ve 3 farklı cam elyaf destekli deney grubu oluşturulmuştur. Üretilen malzemenin, eğilme direnci, elastikiyet modülü, çekme-makaslama direnci, şok direnci, yoğunluğu, kalınlığına şişme ve su alma gibi bazı önemli teknolojik özellikleri belirlenmiştir. Test sonuçlarına göre, cam elyaf dokuma desteğinin yoğunluğu, elastikiyet modülünü ve şok direncini önemli derecede artırdığı, çekme-makaslama direncini, kalınlığına şişme ve su alma yüzdelerini azalttığı belirlenmiştir.
\end{abstract}

Anahtar kelimeler: Cam elyaf, Tabakalı kaplama kereste, mekanik özellikler, fiziksel özellikler

\section{Some Technological Properties of Laminated Veneer Lumber Reinforced With Woven Glass Fiber}

\begin{abstract}
Woven glass-fiber is used in many different areas for the aim of reinforcement. Some important investigations were made by some other researchers about reinforcement of wood material by using glass-fiber. But, in these studies, generally, it was aimed the increase of mechanical performance by applying the glass-fiber to the tension zone of the load carrying members. In present study, laminated veneer lumber was produced using woven glass-fiber and poplar veneer. One control group and three different test groups with woven glass-fiber were created. Modulus of rapture, modulus of elasticity, tensile-shear strength, impact bending, density, thickness swelling, and water absorption were determined. According to test results; it was determined that the reinforcement with woven glass-fiber significantly increased density, modulus of elasticity, and impact bending, and decreased the tensileshear strength, thickness swelling and water absorption percentages.
\end{abstract}

Keywords: Glass-fiber, laminated veneer lumber, mechanical properties, physical properties

\section{GíRiş̧}

Masif ağaç malzemenin yapıda kullanımını sınırlayan bazı istenmeyen özellikleri bulunmaktadır. Üç farklı yönde farklı özellikler göstermesi sebebiyle anizotropik bir malzeme olması, budak olan noktalardan kırılma riskinin oldukça yüksek olması, ölçülerinin sınırlı olması, piyasada standart bazı ölçülerde bulunamaması ve biyolojik dayanıklılığının düşük olması gibi istenmeyen özellikleri bulunmaktadır. Ayrıca, enine kesitte öz odun-diri odun arasında $[1,2]$ ya da genç odun-olgun odun arasında kimyasal, morfolojik, fiziksel ve mekanik özelliklerde [3,4] belirgin bazı farklılıklar bulunmaktadır.Masif ahşabın bu istenmeyen özelliklerinin bazılarının düzeltilmesiiyileştirilmesi amacıyla yapısal kompozit keresteler (SCLs-structural composite lumbers) üretilmeye başlanmıştır.Yapısal kompozit keresteler orijinal isimleriyle LVL (laminated veneer lumber), PSL (paralel strand lumber), OSL (oriented strand lumber) olarak isimlendirilmektedir [5]. LVL Türkçe'ye tabakalanmış kaplama kereste olarak [6] ve Tabakalı kaplama kereste olarak [7] çevrilmiștir. Ancak, bu çalışmada, bu noktadan itibaren orijinal adına bağlı kalınarak LVL olarak kullanılacaktır. LVL en fazla $3.2 \mathrm{~mm}$ kalınlıktaki soyma kaplama levhalarının, lif yönleri birbirine paralel gelecek şekilde, tutkallanıp preslenmesiyle elde edilen levhalardan, piyasa isteklerine göre farklı ölçülerde kesilip hazırlanan bir kerestedir. LVL'nin masif ağaç malzemeye göre görsel kusurlarından arındırılması, daha iyi fiziksel özelliklere sahip olması ve mekanik özelliklerinin aynı türü temsil eden masif ağaç malzemeye göre daha yüksek olması gibi birçok üstün özellikleri olduğu bildirilmektedir [8,9,10,11]. LVL üretiminde genel olarak düşük ve orta yoğunluğa sahip odunlar

*Sorumlu Yazar: Bekir Cihad Bal, bcbal@hotmail.com 
kullanılmaktadır. Geniş yapraklı ağaçlardan Populus tremuloides, Populus balsmifera, Liriodendron tulipifera, Acacia mangium, Gmelina arborea, Albizia falcata ve bazı okaliptüs türleri LVL üretiminde kullanılmakta veya kullanılabilirliği araştırılmaktadır [12]. İğne yapraklı ağaç türlerinden Pseudotsuga menziesi, Picea sitchensis, Tsuga heterophylla ve Southern pines kullanılmaktadır [13,14].Kavak ağacı hızlı büyüyen ağaç türlerindendir [15,16,17]. Düzgün gövde oluşturmaktadır [18]. Yaş haldeyken 1sıtmabuharlama yapılmadan kaplama soyulabilmektedir. Permaabilitesi yüksektir. Bu sebeple kurutulması kolay ve kurutma maliyeti düşüktür. Türkiye'de ve Dünyada kontrplak üretiminde, bu önemli üstünlüklerinden dolayı, fazlaca kullanılan ağaç türlerindendir $[19,20,21,22]$. Ancak, düşük yoğunluğa sahip olduğu için mekanik özellikleri de düşüktür [18]. Biyolojik olarak dayanıksız bir ağaç türüdür [23]. Düşük mekanik özelliklere sahip olan masif odun ya da odun esaslı kompozit malzemeler, değişik bazı yöntemlerle güçlendirilebilmektedir. Güçlendirme için sentetik lifler kullanılmaktadır. Odun ya da odun esasl k kompozit malzemelerin, güçlendirilmesi yeni bir fikir değildir. Laufenberg ve ark. [24] göre 1960'l1 yıllardan beri yapılmaktadır. Sentetik liflerle ahşabın güçlendirilmesi ilk olarak Wangaard [25] ve Biblis [26] tarafından gerçekleştirilmiştir. Kavak LVL in güçlendirilmesine dair çalışmalar Bal [27,28] tarafindan da yapılmıştır. Ancak önceki çalışmalarda, cam elyaf desteği ya çekme bölgesine ya da tutkal tabakalarına yerleştirilmiştir. Farklı şekillerde kombine edilmiş cam elyaf dokuma desteği ile üretilen Kavak LVL hakkında literatürde yeterli bilgi bulunmamaktadır.Bu çalışmanın amacı; farklı kombinasyonlar da cam elyaf ile desteklenmiş kavak LVL levhalarının bazı mekanik ve fiziksel özelliklerinin araştırılmasıdır.

\section{MATERYAL VE METOT}

\subsection{Materyal}

Bu çalışma için Samsun'un Çarşamba ilçesinden elde edilen ve piyasada genel olarak Çarşamba kavağ [29], kavak klonuna ait soyma kaplamalar kullanılmıştır. Soyma kaplamalar özel bir kontrplak fabrikasından satın alınarak temin edilmiştir. Fabrikada, soyma kaplama kalınlığı $2.7 \mathrm{~mm}$, genişliği $650 \mathrm{~mm}$ ve uzunluğu $2000 \mathrm{~mm}$ olacak şekilde ayarlanmıştır. Kaplamaların kurutulması aynı kurutma fabrikasında sağlanmıştır. Kaplamalar fabrikadan, Kahramanmaraş Sütçü İmam üniversitesi orman fakültesi, orman endüstri mühendisliği bölümüne getirilmiştir. Burada kaplamaların genişlik ve uzunlukları 600 x 600 mm olacak şekilde ayarlanmıştır. Kaplama kusuru olarak; çatlak, çürüme, böcek ya da kurt yeniği ve budak gibi kusurlu kaplamalar denemelerde kullanılmamıştır. Temiz ve homojen kaplamalar deneme levhalarının üretiminde kullanılmıştır. Denemelerde bir kontrol ve üç test grubu oluşturulmuştur. Üç test grubunda güçlendirme için cam elyaf dokuma kullanılmıştır. Cam elyaf dokuma özel bir imalatçıdan satın alınma yoluyla tedarik edilmiştir. Cam elyaf dokumanın yoğunluğu $500 \mathrm{~g} / \mathrm{m}^{2}$ 'dir. Dokuma tipi "bez ayağı" şeklindedir. LVL levhaları 8 tabakalı olarak üretilmiştir. Kontrol grubunda cam elyaf dokuma kullanılmamıştır. Güçlendirilmiş LVL'de ise 3 farklı kombinasyonda cam elyaf dokuma kullanılmıştır. Bunlar cam elyaf dokumanın kullanıldığı yere göre; sadece yüzeylere (Grup:A), tüm tutkal tabakalarına (Grub: B) ve sadece yüzeylere ve bitişik tutkal tabakasına (Grup:C) olmak üzere 3 grup şeklindedir. Demelerde kullanılan tutkal özel bir tutkal üreticisinden tedarik edilmiştir. Tutkal miktarı her tabaka için ortalama $200 \mathrm{~g} / \mathrm{m}^{2}$ uygulanmıştır. Pres basıncı $7 \mathrm{~kg} / \mathrm{cm}^{2}$ olarak ayarlanmıştır. Preslemeden sonra levhalar 1 hafta üst üste istif edilmiş ve bekletilmiş ve sonra test örnekleri hazırlanmıştır.

\subsection{Metot}

Üretilen levhaların bazı fiziksel ve mekanik özellikleri belirlenmiștir. Fiziksel özelliklerden rutubet TS EN 322'e [30] göre, yoğunluk TS EN 323'e [31] göre, su alma ve kalınlığına şişme TS EN 317'e [32] göre, mekanik özelliklerden ise eğilme direnci ve elastikiyet modülü TS EN 310'a [33] göre, şok direnci TS 2477'e [34] göre ve çekme makaslama direnci TS EN 314-1[35] ve TS EN 314-2'de [36] belirtilen kriterler dikkate alınarak yapılmıştır.Elde edilen veriler SPSS programı kullanılarak istatistiksel olarak değerlendirilmiştir. Farklı katmanlarda uygulanan cam elyaf dokuma desteğinin fiziksel ve mekanik özellikler üzerine etkisi tek yönlü varyans analizi (One-way ANOVA) ile ve bu grupların ortalamaları arasındaki farklar Tukey HSD (Tukey Honestly Significant Difference) çoklu karşılaştırma testi ile belirlenmiştir. Fiziksel özellikleri belirlemek için her grupta 30 örnek, mekanik özellikleri belirlemek için ise her grupta 25 test örneği hazırlanmıştır.

\section{BULGULAR VE TARTIŞMA}

\subsection{Hava Kurusu Yoğunluk, Kalınlığına şişme ve su alma testi}

Hava kurusu yoğunluk, kalınlığına şişme, su alma testi sonuçları, bu sonuçlar arasında fark olup olmadığını gösteren ANOVA testi önem düzeyleri ve hangi grupların birbirinden farklı olduğunu 
gösteren Tukey testi sonuçları Çizelge 1'de verilmiştir.

Çizelge 1. Hava kurusu yoğunluk, kalınlığına şişme ve su alma testi sonuçları, ANOVA önem düzeyi ve Tukey testi sonuçları.

\begin{tabular}{|c|c|c|c|c|c|c|c|c|c|}
\hline Grup & $\mathbf{N}$ & & $\mathrm{D}\left(\mathrm{gr} / \mathrm{cm}^{3}\right)$ & $\begin{array}{c}\text { KS } \\
2 \text { saat }\end{array}$ & $\begin{array}{c}\text { KŞ } \\
24 \text { saat }\end{array}$ & $\begin{array}{c}\text { KŞ } \\
\text { 336saat }\end{array}$ & $\begin{array}{c}\text { SA } \\
\text { 2saat }\end{array}$ & $\begin{array}{c}\text { SA } \\
\text { 24saat }\end{array}$ & $\begin{array}{c}\text { SA } \\
\text { 336saat }\end{array}$ \\
\hline \multirow[t]{2}{*}{ Kontrol } & 30 & $\mathrm{x}$ & $0,450 \mathbf{a}$ & 1,4 b & $2,7 \mathbf{a}$ & 3,7 & $24,0 \mathbf{a}$ & $60,18 \mathbf{b}$ & $119 \mathrm{c}$ \\
\hline & & $\mathrm{s}$ & & 0,1 & 0,07 & 0,3 & 2,77 & 5,28 & 11,4 \\
\hline \multirow[t]{2}{*}{ A } & 30 & $\mathrm{x}$ & 0,475 b & $1,38 \mathbf{b}$ & $2,68 \mathbf{a}$ & 3,68 & $36,03 \mathbf{b}$ & $62,74 \mathbf{b}$ & $111 \mathrm{c}$ \\
\hline & & $\mathrm{s}$ & & 0,07 & 0,16 & 0,26 & 4,74 & 4,89 & 4,8 \\
\hline \multirow[t]{2}{*}{ B } & 30 & $\mathrm{x}$ & $0,574 \mathrm{c}$ & $1,34 \mathbf{a}$ & $2,64 \mathbf{a}$ & 3,59 & 24,83 a & $48,56 \mathbf{a}$ & $100 \mathbf{b}$ \\
\hline & & $\mathrm{s}$ & & 0,07 & 0,11 & 0,36 & 2,31 & 2,34 & 0,9 \\
\hline \multirow[t]{2}{*}{ C } & 30 & $\mathrm{x}$ & $0,557 \mathbf{c}$ & $1,32 \mathbf{a}$ & $2,64 \mathbf{a}$ & 3,64 & 25,55 a & $50,03 \mathbf{a}$ & $103 \mathbf{a}$ \\
\hline & & $\mathrm{s}$ & & 0,09 & 0,16 & 0,33 & 3,01 & 3,09 & 3,3 \\
\hline Önem düz & & & $* * *$ & $* *$ & * & NS & $* * *$ & $* * *$ & $* * *$ \\
\hline
\end{tabular}

N: gruptaki örnek sayısı, D: hava kurusu yoğunluk miktarı, KŞ: kalınlığına şişme, SA: Su alma, x: aritmetik ortalama, s: standart sapma.

Elde edilen bulgular incelendiğinde, ANOVA testi sonucunda hava kurusu yoğunluk miktar1 kontrol grubunda $0.450 \mathrm{~g} / \mathrm{cm}^{3}$ ve diğer A, $\mathrm{B}, \mathrm{C}$ gruplarında ise sirasıyla $0.475,0.574$ ve 0.557 $\mathrm{g} / \mathrm{cm}^{3}$ olarak belirlenmiştir. Gruplar arasındaki farklıl1k istatistiksel olarak önemli bulunmuştur (p $<0.001$ ). En yüksek yoğunluk B grubunda elde edilmiştir.Tukey çoklu karşılaştırma testi incelendiğinde, elde edilen sonuçlara göre kontrol grubu, A grubu, B grubu ve C grubu hava kurusu yoğunluk miktarları farklı bulunmuştur. $\mathrm{Bu}$ durumun güçlendirme yapılan $A, B$ ve $C$ gruplarının her birinde farklı sayıda cam elyaf dokuma tabakasının kullanılması ve bunların yapıştırılması için kullanılan tutkal miktarındaki fazlalıktan kaynaklandığı söylenebilir [7,10,28,37]. Kalınlığına şişme miktarları için yapılan ANOVA testi sonucunda elde edilen bulgular incelendiğinde, 2 saat suda bekletme sonucunda, gruplar arasındaki farklılıklar 0,01 yanılma olasılığ bekletme sonucunda 0,05 yanılma olasıll $\breve{g ̆}_{1}$ ile istatistiksel olarak önemli bulunmuştur. 336 saat süre sonucunda kalınlığına şişme yüzdeleri arasında istatistiksel olarak bir farklılık belirlenmemiştir. Kalınlığına şişme miktarları için yapılan Tukey çoklu karşılaş̧ırma testi incelendiğinde elde edilen sonuçlara göre 2, 24 ve 336 saat sonucunda en yüksek değerler kontrol grubunda, en düşük değerler ise 2 ve 24 saat sonucunda $C, 336$ saat sonucunda ise B grubunda ölçülmüştür. Bu ölçülen değerler incelendiğinde sonuçların birbirine yakın olduğu görülmekte fakat en yüksek değerlerin yoğunluğu düşük olan kontrol grubunda, en düşük değerlerin ise yoğunluğu kontrol grubuna göre nispeten daha yüksek olan $\mathrm{B}$ ve $\mathrm{C}$ gruplarında ölçülmüş olmasının, kaplamaların tutkal ile modifiye olmasından kaynaklandığı tahmin edilmektedir [28]. Su alma testi ile elde edilen bulgular incelendiğinde, yapılan ANOVA testi sonucunda 2, 24 ve 336 saat suda bekletme sonucunda ölçülen değerlerin istatistiksel olarak farklı olduğu belirlenmiştir $(\mathrm{p}<0.001)$. Su alma değerleri için yapılan Tukey HSD çoklu karşılaştırma testi sonuçlarına göre 24 ve 336 saat sonucunda en yüksek değerler yoğunluğu düşük olan kontrol grubunda, en düşük değerler ise 2, 24 ve 336 saat sonucunda yoğunluğu yüksek olan B grubunda ölçülmüştür. B grubunda ölçülen su alma yüzdelerinin en düşük olmasının sebebinin, kullanılan cam elyaf dokuma olduğu ve bu grupta diğerlerine göre fazla tutkal kullanılmasından kaynaklandığı söylenebilir. Cam elyafla güçlendirilmiş tabakalı malzemenin kalınlığına şişme ve su alma yüzdeleri üzerine literatürde az sayıda çalışma bulunmaktadır. Örneğin; Bal [28] tarafindan yapılan bir çalışmada FF tutkalı kullanılarak üretilen kavak LVL' de 504 saat suda bekletme sonunda kalınlığına, genişliğine ve hacmen şişme yüzdeleri kontrol grubu ile deney grubu arasında önemli seviyede farklı bulunmuştur. Su alma yüzdelerinin deney gruplarında daha düşük olduğu rapor edilmiştir. Ayrıca, Wang and Chui [37, 38] FF tutkalı ile muamele edilmiş LVL levhalarında kalınlığına şişme ve su alma yüzdelerinin kontrol levhalarına göre daha düşük olduğu belirlenmiştir. 


\subsection{Eğilme Direnci ve Elastikiyet Modülü}

Eğilme direnci, elastikiyet modülü ve şok direnci testine ait bulgular, bu bulguların değerlendirildiği ANOVA testi önem düzeyleri ve gruplar arasındaki farkları gösteren Tukey testi sonuçları Çizelge 2'de verilmiştir. Eğilme direnci, elastikiyet modulü ve şok direncinde önemli farkların olduğu görülmektedir.

Çizelge 2. Eğilme direnci, Elastikiyet Modülü, şok direnci testi sonuçları, ANOVA testi önem düzeyleri ve TUKEY testi sonuçları.

\begin{tabular}{|c|c|c|c|c|c|}
\hline Grup adı & $\mathrm{N}$ & $\begin{array}{c}\text { Ĕgilme direnci } \\
\left(\mathrm{N} / \mathrm{mm}^{2}\right)\end{array}$ & $\begin{array}{c}\text { Elastikiyet modülü } \\
\left(\mathrm{N} / \mathrm{mm}^{2}\right)\end{array}$ & $\mathrm{N}$ & $\begin{array}{c}\text { Sok direnci } \\
\left(\mathrm{kgm} / \mathrm{cm}^{2}\right)\end{array}$ \\
\hline Kontrol & 25 & $67,86 \mathbf{a b}$ & $5602 \mathbf{a}$ & 30 & $0,378 \mathbf{a}$ \\
\hline A & 25 & $64,76 \mathbf{a}$ & $6562 \mathbf{b}$ & 30 & $0,454 \mathbf{b}$ \\
\hline B & 25 & $67,77 \mathbf{a b}$ & $7502 \mathbf{d}$ & 30 & $0,737 \mathbf{d}$ \\
\hline C & 25 & $70,03 \mathbf{b}$ & $7035 \mathbf{c}$ & 30 & $0,596 \mathbf{c}$ \\
\hline \multicolumn{2}{|c|}{ Önem düzeyi } & $*$ & $* * *$ & & $* * *$ \\
\hline
\end{tabular}

Eğilme direnci değerleri Tukey çoklu karşllaştırma testine göre, en yüksek eğilme direnci değeri $70,03 \mathrm{~N} / \mathrm{mm}^{2}$ ile güçlendirme işlemi yapılmış olan $C$ grubunda, en düşük değer ise 64,76 $\mathrm{N} / \mathrm{mm}^{2}$ A grubunda ölçülmüştür. Yapılan güçlendirme çalışmalarının üretilen malzemenin eğilme direncini sadece $\mathrm{C}$ grubunda pozitif yönde etkilediği görülmektedir. Cam elyaf dokuma ile güçlendirilmiş $\mathrm{LVL}$ gruplarından $\mathrm{C}$ grubunun eğilme direnci kontrol grubundan daha yüksek ölçülmüştür. Diğer deney gruplarında önemli bir artış ölçülememiştir. Bunun, dış yüzeylere yapıştırılan cam elyafinın, test örneğinin kalınlığının artmasına sebep olurken, eğilme direnci formülüne göre ters orantılı olduğu için, direncinin azalmasına sebep olmuştur. Cam elyafla güçlendirme üzerine yapılan bazı önceki çalışmalarda da benzer sonuçlar elde edilmiştir. Hallstrom ve Grenestedt [39] yapmış oldukları çalı̧̧mada, cam elyafi ile güçlendirilmiş ahşap lamine kirişlerde, cam elyafi ile güçlendirilmiş deney numunelerindeki çatlakların, güçlendirilmemiş kirişlere nazaran daha yavaş ilerlemekte olduğunu ve güçlendirmenin çatlama durdurucu görevi üstlendiğini bildirmişlerdir. Basterra ve ark. [40] kavak odunundan elde edilen çift kirişlerin (duo beams) cam elyafi, carbon elyafı ve keten elyafı ile güçlendirilmesi üzerine yapmış oldukları çalışmada, cam elyafı ve keten elyafı ile yapılan güçlendirmede istatistiksel olarak önemli bir artış belirlenmemiştir. Benzer şekilde Bal [27] tarafindan yapılan çalışmada, $800 \mathrm{gr} / \mathrm{m} 2$ cam elyaf dokuma ile kavak kaplamalarından elde edilen LVL güçlendirme yapılmış, eğilme direncinde çok yüksek bir artış kaydedilememiştir.
Tukey HSD çoklu karşılaştırma testine göre elastikiyet modülü değerleri, en yüksek 7502 $\mathrm{N} / \mathrm{mm}^{2}$ ile B grubunda, en düşük değer ise 5602 $\mathrm{N} / \mathrm{mm}^{2}$, kontrol grubunda ölçülmüştür. Yapılan güçlendirme çalışmalarının üretilen malzemenin elastikiyet modülünü pozitif yönde etkilediği görülmektedir. Güçlendirme yapılan A, B ve C gruplarında sonuçlar sırasıyla $7502 \mathrm{~N} / \mathrm{mm}^{2}, \quad 7035$ $\mathrm{N} / \mathrm{mm}^{2}$ ve $6562 \mathrm{~N} / \mathrm{mm}^{2}$ olarak, kontrol grubunda ise $5602 \mathrm{~N} / \mathrm{mm}^{2}$ ölçülmüştür. Güçlendirme çalışması yapılan grupların kontrol grubuna kıyasla A grubunda \% 17.1, B grubunda \% 34, C grubunda $\% 25,6$ lık bir artış kaydedilmiştir. Elastikiyet modülü hakkında, benzer sonuçlar Bal [27] tarafindan da bulunmuştur.Şekil 1, 2, 3 ve 4 incelendiğinde güçlendirme işlemi yapılmamış olan kontrol grubu ile güçlendirme işlemi yapılan A, B ve $\mathrm{C}$ grupları birbirlerinden farklı kırılma eğrilerinin oluştuğu görülmektedir. Bu kırılma şekillerini incelediğimizde kontrol grubunda çok ani bir kırılma meydana gelirken güçlendirme işlemleri yapılan gruplarda ise kademeli bir kırılma meydana gelmektedir. Bunun nedeninin cam elyafın genel yapısı olduğu düşünülmektedir.

Çizelge 2'de verilen şok direnci değerleri incelendiğinde, grupların önemli derecede farklı olduğu, en yüksek şok direncinin $\mathrm{B}$ grubunda ölçüldügü görülmektedir. En düşük değer ise 0,378 $\mathrm{kgm} / \mathrm{cm}^{2}$ kontrol grubunda ölçülmüştür. Yapılan güçlendirme çalışmalarının üretilen malzemenin şok direncini güçlü bir şekilde pozitif yönde etkilediği ve daha güçlü hale getirdiği belirlenmiştir. Güçlendirme çalışılması yapılan grupların kontrol grubuna kiyasla A grubunda \% 20.1, B grubunda $\% 95$ ve C grubunda $\% 58$ arttı görülmektedir. Şok direnci üzerine benzer sonuçlar, 
Bal [28] tarafindan yapılan çalışmada cam elyaf dokuma $\left(800 \mathrm{~g} / \mathrm{m}^{2}\right)$ ile güçlendirme çalışması yapılan ve fenol formaldehit tutkalı ile üretilen

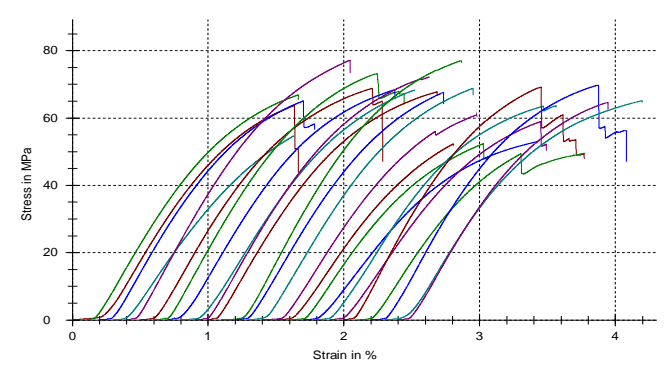

Şekil 1. Kontrol grubunda gerilim-gerinim grafiği

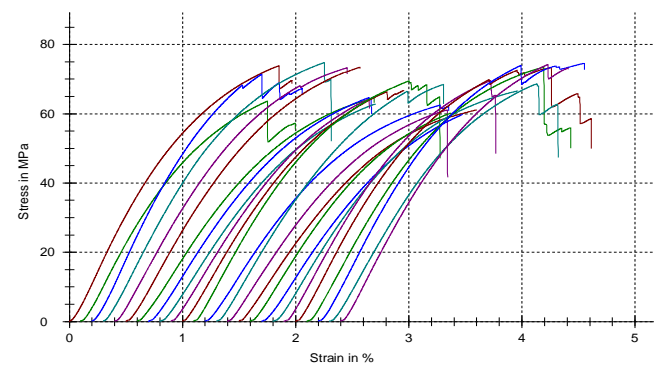

Şekil 2. A grubunda gerilim-gerinim grafiği

\section{5. Çekme-Makaslama direnci}

Çekme-makaslama direnci testleri kontrol ve B gruplarında, üç farklı tutkal tabakasında yapılmıştır. Testler hava kurusu halde ve sıcak su ile ön işlem uyguladıktan sonra olmak üzere iki farklı grupta yapılmıştır. Çekme-makaslama testine ait bulgular Çizelge 3'te verilmiştir. B grubunun Çekme Makaslama Direnci, kontrol grubuna kavak LVL levhaların şok direnci, kontrol grubuna göre; radyal yüzeyde \%113, teğet yüzeyde ise \% 154 lük bir artış kaydedildiği bildirilmiştir.

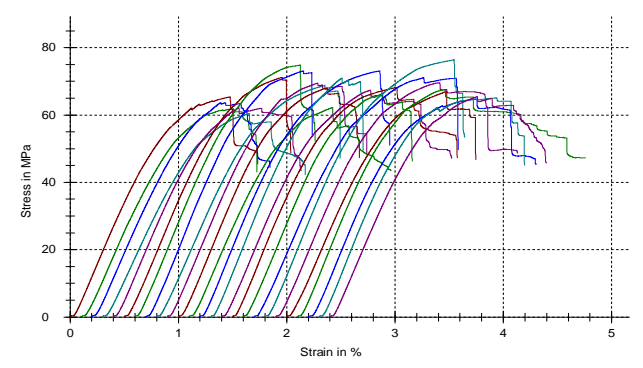

Şekil 3. B grubunda gerilim-gerinim grafiği

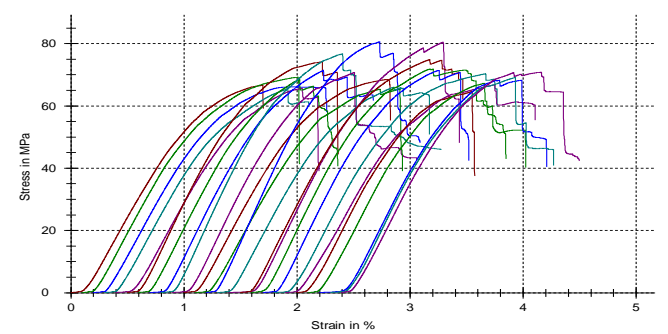

Şekil 4. C grubunda gerilim-gerinim grafiği

kıyasla hem hava kurusu hem de yaş halde daha düşük çıkmıştır. Bunun sebebinin güçlendirme çalışmasında kullanılan cam elyaf kumaşının, pürüzlü yüzey yapısından levha tabakalarına tam olarak temas etmemesinden kaynaklandiğ düşünülmektedir. Bal [27] tarafindan yapılan çalışmada benzer sonuçlar bildirilmiştir.

Çizelge 3. Hava kurusu örneklerde çekme-makaslama test sonuçları

\begin{tabular}{|c|c|c|c|c|}
\hline \multicolumn{5}{|c|}{ Hava Kurusu halde test edilen örnekler } \\
\hline & & \multicolumn{3}{|c|}{ Tutkal Tabakası } \\
\hline & & 3 & 4 & 5 \\
\hline \multirow{3}{*}{$\begin{array}{c}\text { Kontrol } \\
\text { grubu }\end{array}$} & Ort. $\left(\mathrm{N} / \mathrm{mm}^{2}\right)$ & 1. 4.76 & 5.01 & 5.34 \\
\hline & SS & 0.7 & 1.2 & 1.4 \\
\hline & OK (\%) & 77 & 50 & 50 \\
\hline \multirow{3}{*}{ B grubu } & Ort. $\left(\mathrm{N} / \mathrm{mm}^{2}\right)$ & 3.62 & 4.35 & 3.35 \\
\hline & SS & 0.6 & 1.1 & 0.3 \\
\hline & COK (\%) & 28 & 12 & 18 \\
\hline \multicolumn{5}{|c|}{ Sıcak su ile ön işlem yapılan örnekler } \\
\hline & & \multicolumn{3}{|c|}{ Tutkal Tabakası } \\
\hline & & 3 & 4 & 5 \\
\hline \multirow{3}{*}{$\begin{array}{c}\text { Kontrol } \\
\text { grubu }\end{array}$} & Ort. $\left(\mathrm{N} / \mathrm{mm}^{2}\right)$ & 3.14 & 3.0 & 3.5 \\
\hline & SS & 0.5 & 0.5 & 0.6 \\
\hline & OK (\%) & 24 & 13 & 11 \\
\hline \multirow{3}{*}{$\mathrm{B}$ grubu } & Ort. (N/mm²) & 1.7 & 2.1 & 2.1 \\
\hline & SS & 0.2 & 0.3 & 0.3 \\
\hline & COK (\%) & 16 & 11 & 12 \\
\hline
\end{tabular}

Ort: ortalama, ss: standart sapma, OK: odun kırılması, COK, cam elyaf kırılması 


\section{SONUÇLAR VE ÖNERÍLER}

Yapılan bu çalışmada, cam elyaf dokuma ile güçlendirilmiş LVL levhaların bazı fiziksel ve mekanik özellikleri araştırılmıştır. Cam elyafın yoğunluğunun oduna göre daha yüksek olması sebebiyle, üretilen güçlendirilmiş LVL'in yoğunluğu daha yüksek ölçülmüştür. Kalınlığına şişme ve su alma testlerinde ise, cam elyafi ile güçlendirilmiş levhaların daha fazla tutkal kullanılması sebebiyle, 2 ve 24 saatte kalınlığına şişme yüzdeleri düşük bulunmuştur. 2 saat sonunda ölçülen su alma yüzdesi ise A grubunda daha yüksek ölçülmüsşür. Bunda cam elyaf dokumanın gözenekli bir yapıya sahip olmasının etkili olduğu düşünülmektedir. Yapılan güçlendirme ile eğilme direncinde önemli bir artış ölçülememiştir. Ancak elastikiyet modülü ve şok direncinde önemli artışlar ölçülmüştür. Yapışma performansının ölçüldüğü çekme-makaslama testinde ise kontrol grubuna göre deney grubunun yapışma performansı daha düşük ölçülmüsstür. Düşük yoğunluğa ve düşük ekonomik değere sahip olan ağaç türlerinden elde edilen lamine malzemelerin güçlendirilmesi ile yüksek fiziksel ve mekanik performansa sahip güçlendirilmiş LVL üretilerek ekonomik faydalar sağlanacağı düşünülmektedir. Ekonomik değeri yüksek güçlendirilmiş LVL üretilmesi ve bunun yaygınlaşması, ekonomik açıdan fayda sağlayabilir. Cam elyaf ile güçlendirilmiş LVL'in şok direncinin oldukça arttığı belirlenmiştir. Ülkemizin deprem bölgesinde olması sebebiyle, özellikle yap1 sektöründe yük taşıyıcı olarak kullanılan LVL gibi ahşap esaslı malzemelerin, güçlendirme işlemleri yapılmış malzemelerden seçilmesi ve kullanılmasının, depremin yıkıcı etkisini azaltmada önemli rol oynayacağ 1 düşünülmektedir.

\section{TEŞEKKÜR}

$\mathrm{Bu}$ çalışma Kahramanmaraş Sütçü İmam Üniversitesi araştırma projeleri yönetim birimi başkanlığı tarafından 2013/7-2 YLS numaralı proje ile desteklenmiştir.

\section{KAYNAKLAR}

[1] Bal, B. C., Bektaş, I. (2012). "The physical properties of heartwood and sapwood of Eucalyptus grandis” Pro Ligno, 8(4), 35-43.

[2] Bal, B. C., Bektaş, İ. (2013a). "The Mechanical Properties of Heartwood and
Sapwood of Flooded gum (Eucalyptus grandis) Grown in Karabucak, Turkey.” Düzce Üniversitesi Ormancilık Der, 9 (1) : 71-76

[3] Bal, B. C., Bektaş, İ., Kaymakçı, A. (2012). "Toros sedirinde genç odun ve olgun odunun bazı fiziksel ve mekanik özellikleri”. KSÜ, Mühendislik Bilimleri Dergisi 15(2).

[4] Bal, B. C. (2012). "Genç odun ve olgun odunun lif morfolojisindeki farklılıklar üzerine bir araştırma". Düzce Üniversitesi Ormanc1lık Dergisi, 8(2), 29-35.

[5] Güller, B., (2001) “Odun kompozitleri,” Süleyman Demirel Üniversitesi Orman Fakültesi Dergisi Seri: 2, (A): 135-160.

[6] Kurt, R., Mengeloğlu, F., Çavuş, V., (2008) "Okaliptüs odununun kullanımında yeni alanlar”, I. Ulusal Okaliptüs Sempozyumu Bildiriler Kitab1, S:84.

[7] Bal, B. C., and Bektaş, İ. (2013b). "Some physical properties of laminated veneer lumbers (LVLs) produced from rotary-peeled veneers of eucalyptus, beech, and poplar.” Artvin Çoruh University Journal of Forestry Faculty, 14(1), 25-35.

[8] Bao F, Fu F, Choong E T and Hse C, (2001). "Contribution Factor of Wood Properties of Three Poplar Clones to Strength of Laminated Veneer Lumber," Wood and Fiber Science, 33 (3) : 345-352.

[9] Burdurlu E, Kılıç M, İlce A C ve Uzunkavak O, (2007) "The Effects of Ply Organization and Loading Direction on Bending Strength and Modulus of Elasticity in Laminated Veneer Lumber (LVL) Obtained From Beech (Fagus orientalis L.) and Lombardy poplar (Populus nigra L.)" Construction and Building Materials 21: 1720-1725.

[10] Shukla S R and Kamdem P D, (2009) "Properties Of Laboratory Made Yellow Poplar (Liriodendron Tulipifera) Laminated Veneer Lumber: Effect Of The Adhesives, Eur. Journal.” Wood Product 67: 397-405.

[11] Bal, B. C., Özdemir, F., Altuntaş, E. (2013) "Masif Ağaç Malzeme ve Tabakalı Kaplama Kerestenin Vida Tutma Direnci Üzerine 
Karşılaştırmalı Bir Çalışma”, Düzce Üniversitesi Ormancılık Dergisi, 9 (2) : 1422.

[12] Ozarska, B.,(1999) "A review of the utilization of hardwoods for LVL," Wood Science and Technology 33: 341-351.

[13] Moody RC., Hernandez R. Liu JY, (1999) "Glued structural members, Wood handbook, Wood as Engineering Material.” FPL,GTR, 113, P:2-3, Madison.

[14] Berlung, L., Rowell, R.M., (2005) "Wood Composites," Handbook of Wood Chemistry and Wood Composites.

[15] Tunçtaner, K., Tulukçu, M., Toplu, F., (1994) "Bazı kavak klonlarının büyümeleri ve teknolojik özellikleri üzerine araştırmalar," kavak ve hızlı gelişen tür orman ağaçları araştırma enstitüsü, Teknik Bülten No: 170. İzmit

[16] Tunçtaner, K., As, N., Özden, Ö., (2004) "Bazı kavak klonlarının büyüme performansları, odunlarının bazı teknolojik özellikleri ve kağıt üretimine uygunlukları üzerine araştırmalar," Kavak ve Hızlı Gelişen Tür Orman Ağaçları Araştırma Enstitüsü, Teknik Bülten No: 196. İzmit.

[17] Ayan, S., Sivacioğlu, A. (2006) "Review of the fast growing forest tree species in Turkey”, Boletín del CIDEU 2: 57-71.

[18] Bozkurt, Y., Erdin, N., (1997). "Ağaç Teknolojisi Ders Kitabı”, İ.Ü. Orman Fakültesi, Yayın no: 445, S: 1, İstanbul.

[19] Çolakoğlu, G., (1996) “Tabakalı Ağaç Malzeme Teknolojisi Ders Notları (Yayınlanmamış)" KTÜ, Orman Fakültesi, Trabzon.

[20] Kurt, R., (2010) "Suitability of three hybrid poplar clones for laminated veneer lumber manufacturing using melamine urea formaldehyde adhesive,” Bioresources, 5(3), 1868-1878.

[21] Örs, Y., Çolakoğlu, G., Çolak S., (2001) "Kavak (Populus x Eureamericana I 45/51) kontrplaklarının çekme-makaslama ve eğilme direnci ile eğilmede elastiklik modülü üzerine bazı üretim faktörlerinin etkisi," Politeknik Dergisi, 4 (4): 25-32.

[22] Örs, Y., Çolakoğlu, G., Aydın, İ, Çolak S., (2002) "Kayın, okume ve kavak soyma kaplamalarından farklı kombinasyonlarda üretilen kontrplakların bazı teknik özelliklerinin karşılaştırılması," Politeknik Dergisi, 5 (3): 257-265.

[23] Bozkurt, Y., Göker Y, Erdin, N., (1993) "Emprenye tekniğii”, İ.Ü. Orman Fakültesi, Yayın no: 3779, İstanbul.

[24] Laufenberg TL, Rowlands RE, Krueger GP. (1984) "Economic feasibility of synthetic fiber reinforced laminated veneer lumber (LVL),” Forest Prod J 34 (4):15-22.

[25] Wangaard FF. (1964) "Elastic deflection of wood-fiberglass composite beams.” Forest Prod J 13 (6): 256-260.

[26] Biblis EJ. (1965) “Analysis of woodfiberglass composite beams within and beyond the elastic region”. Forest Prod J 15 (2): 81-89.

[27] Bal BC, (2014a) "Flexural properties, bonding performance and splitting strength of LVL reinforced with woven glass fiber," Constr Build Mater, 2014; 51(2014): 9-14.

[28] Bal BC, (2014b) "Some physical and mechanical properties of laminated veneer lumber reinforced with woven glass fiber," Constr Build Mater, 2014; 68 (2014): 120126.

[29] Anonim, (2011) "Melez kavak nedir?, Klon nedir?” http://www.kavak.gov.tr/turkce.html, İMIT

[30] TS EN 322, (1999) “Ahşap Esaslı LevhalarRutubet Miktarının Tayini,” TSE, Ankara.

[31] TS EN 323, (1999) “Ahşap esaslı levhalarBirim hacim ağırlığının tayini,” TSE, Ankara.

[32] TS EN 317, (1999) "Yonga Levhalar ve Lif Levhalar-Su İçerisine Daldırma İşleminden Sonra Kalınlığına Şişme Tayini," TSE, Ankara. 
[33] TS EN 310, (1999) "Ahşap esasli levhalar, Eğilme dayanımı ve eğilmede elastikiyet modülü tayini,” TSE, Ankara.

[34] TS 2477, (1976) “Odunun Çarpmada Eğilme Dayanımının Tayini” Türk Standartları Enstitüsü, Ankara.

[35] TS EN 314-1, (1998) "Kontrplak kaplanmışyapışma kalitesi Bölüm 1; deney metotları,” Türk Standartları Enstitüsü, Ankara.

[36] TS EN 314-2, (1999) “Kontrplak- Yapışma kalitesi- Bölüm 2: Özellikller”, Türk Standartları Enstitüsü, Ankara.

[37] Wang BJ, Chui YH, (2012a) "Performance evaluation of phenol formaldehyde resin impregnated veneers and laminated veneer lumber," Wood and Fiber Science, 44 (1): 513.

[38] Wang BJ, Chui YH, (2012b) "Manufacturing of LVL using cost-effective resin impregnation and lay up technologies," Wood Sci Technol, 46 (6): 1043-1059.

[39] Hallström S, Grenestedt JL. (1997) “Failure analysis of laminated timber beams reinforced with glass fibre composites," Wood sci Technol, 31:17-34.

[40] Basterra, LA, Acuna, L, Casado, M, Lopez, G, Bueno, A, (2012) "Strength testing of Poplar duo beams, Populus $x$ euramericana (Done) Guinier cv. I-214, with fibre reinforcement," Constr Build Mater, 36 (2012): 90-96. 